\title{
Evaluation of an Alcohol Withdrawal Protocol and a Preprinted Order Set at a Tertiary Care Hospital
}

\author{
Karen Ng, Karen Dahri, Ivy Chow, and Michael Legal
}

\begin{abstract}
Background: Alcohol withdrawal protocols involving symptom-triggered administration of benzodiazepine have been established to reduce the duration of treatment and the cumulative benzodiazepine dose (relative to usual care). However, the effects of a protocol combining fixed-schedule and symptom-triggered benzodiazepine dosing are less clear.
\end{abstract}

Objective: To assess the efficacy and safety of a combination fixedscheduled and symptom-triggered benzodiazepine dosing protocol for alcohol withdrawal, relative to usual care, for medical inpatients at a tertiary care hospital.

Methods: A chart review of admissions to the internal medicine service for alcohol withdrawal was conducted to compare treatment outcomes before (October 2005 to April 2007) and after (October 2007 to April 2009) implementation of the combination protocol. The primary outcome was duration of benzodiazepine treatment for alcohol withdrawal. The secondary outcomes were cumulative benzodiazepine dose administered, safety implications, and use of adjunctive medications.

Results: A total of 159 patients met the inclusion criteria. Assessable data were available for 71 charts from the pre-implementation period and 72 charts from the post-implementation period. The median duration of benzodiazepine treatment was $91 \mathrm{~h}$ before implementation and $57 \mathrm{~h}$ after implementation $(p<0.001)$. Use of the protocol was also associated with a significant reduction in severe complications of alcohol withdrawal $(50 \%$ versus $33 \%, p=0.019$ ), median cumulative benzodiazepine dose (in lorazepam equivalents) (20.0 mg versus $15.5 \mathrm{mg}, p=0.026)$, and use of adjunctive medications $(65 \%$ versus $38 \%, p=0.001)$. The incidence of serious adverse outcomes of treatment with benzodiazepines was not significantly different between the 2 groups.

Conclusions: Implementation of an alcohol withdrawal protocol with a combination of fixed-schedule and symptom-triggered benzodiazepine dosing in a medical ward was associated with a shorter duration of benzodiazepine use and a lower incidence of severe complications of alcohol withdrawal.

Key words: alcohol withdrawal protocol; Clinical Institute Withdrawal Assessment for Alcohol, revised; symptom-triggered therapy; fixed-schedule therapy; benzodiazepine

\section{RÉSUMÉ}

Contexte : Les protocoles de sevrage alcoolique impliquant l'administration de benzodiazépine adaptée à la symptomatologie ont été mis en place pour réduire la durée du traitement et la dose cumulative de benzodiazépine (par comparaison aux soins habituels). Cependant, les effets d'un protocole combinant l'administration de benzodiazépines à horaire fixe et adaptée à la symptomatologie sont moins clairs.

Objectif : Évaluer l'efficacité et l'innocuité d'un protocole de sevrage alcoolique combinant l'administration de benzodiazépines à horaire fixe et adaptée à la symptomatologie, par comparaison aux soins habituels, chez des patients hospitalisés dans un service médical d'un hôpital de soins tertiaires.

Méthodes: Une analyse des dossiers médicaux des patients hospitalisés dans un service de médecine interne pour un sevrage alcoolique a été effectuée afin de comparer les résultats du traitement avant (entre octobre 2005 et avril 2007) et après (octobre 2007 à avril 2009) la mise en œuvre du protocole mixte. Le principal paramètre d'évaluation était la durée du traitement par les benzodiazépines pour le sevrage alcoolique. Les paramètres d'évaluation secondaires étaient la dose cumulative de benzodiazépines administrée, les répercussions sur l'innocuité et le recours à des médicaments d'appoint.

Résultats : Un total de 159 patients ont satisfait aux critères d'inclusion. Des données évaluables étaient disponibles pour 71 dossiers médicaux dans la période précédant la mise en ouvre du protocole et pour 72 dossiers médicaux dans la période suivant la mise en œuvre du protocole. La durée médiane du traitement par les benzodiazépines pour chaque période ci-dessus était de 91 et 57 heures, respectivement $(p<0.001)$. Lutilisation de ce protocole a également été associée à une réduction significative des complications graves du sevrage alcoolique $(50 \%$ contre $33 \% ; p=0,019$ ), de la dose cumulative médiane de benzodiazépines (en équivalent-lorazépam) (20,0 $\mathrm{mg}$ contre $15,5 \mathrm{mg}, p=0,026)$ et du recours à un médicament d'appoint $(65 \%$ contre $38 \%, p=0,001)$. La fréquence des conséquences indésirables sérieuses du traitement par les benzodiazépines n'était pas significativement différente entre les deux groupes.

Conclusions : La mise en œuvre d'un protocole de sevrage alcoolique combinant l'administration de benzodiazépines à horaire fixe et adaptée à la symptomatologie dans un service médical a été associée à un traitement par les benzodiazépines plus court et à une fréquence moindre des complications sérieuses du sevrage alcoolique. 
Can J Hosp Pharm 2011;64(6):436-445
Mots clés : protocole de sevrage alcoolique; Clinical Institute Withdrawal Assessment for Alcohol, révisée; traitement adapté à la symptomatologie; traitement à horaire fixe; benzodiazépine

[Traduction par l'éditeur]

\section{INTRODUCTION}

A cohol withdrawal syndrome, which is prevalent among hospital inpatients who are heavy and prolonged drinkers, ${ }^{1}$ results from abrupt cessation of chronic alcohol use. The constellation of symptoms associated with alcohol withdrawal can range from minor anxiety and tremors to severe complications, such as seizures, hallucinations, delirium tremens, and death. ${ }^{1}$ Symptoms of alcohol withdrawal syndrome may appear from 6 to $96 \mathrm{~h}$ after the person's last drink, ${ }^{2}$ but its occurrence and progress cannot be reliably predicted, necessitating close monitoring and rapid treatment. The first-line agents for alcohol withdrawal are benzodiazepines, ${ }^{3}$ which can be used to treat the range of minor to severe complications that can occur.

The Clinical Institute Withdrawal Assessment for Alcohol, revised (CIWA-Ar) (see Appendix 1, available online at www.cjhp-online.ca/index.php/cjhp/issue/view/84/showToc), a validated assessment tool to guide benzodiazepine dosing in alcohol withdrawal, ${ }^{4}$ is used extensively as part of symptomtriggered dosing regimens for benzodiazepines. This type of regimen promotes real-time coordination of the benzodiazepine dose to the severity of symptoms. ${ }^{5}$ The CIWAAr is used to objectively quantify and evaluate the patient's progress during alcohol withdrawal. This 10-item scale, which takes approximately $5 \mathrm{~min}$ to administer, helps to determine the need for medication and additional monitoring, ${ }^{6,7}$ thereby decreasing the risk of under- or over-treatment. ${ }^{8}$ With inpatient programs for treating chemical dependency, the symptomtriggered regimen has been demonstrated to result in a decrease in total benzodiazepine dose and shorter duration of benzodiazepine treatment relative to a fixed-schedule regimen in both prospective $^{7,9}$ and retrospective ${ }^{8}$ trials. Likewise, for patients with comorbidities being treated in general hospital wards, symptom-triggered dosing regimens resulted in lower incidence of delirium tremens, shorter duration of benzodiazepine treatment, ${ }^{8}$ and a lower total benzodiazepine dose. ${ }^{10}$

Despite the clear benefit of symptom-triggered dosing with the CIWA-Ar scale, many institutions still use fixedschedule dosing regimens for benzodiazepines, because symptom-triggered dosing is more labour-intensive and requires trained clinical staff and sufficient resources. ${ }^{11}$ For busy hospital wards with insufficient numbers of fully trained nurses on staff to perform intensive CIWA-Ar monitoring for symptom-triggered dosing, fixed-schedule dosing is an appropriate alternative to ensure a margin of safety, provided there is an understanding that unnecessary doses of benzodiazepines may be administered. ${ }^{10}$

In 2005, a retrospective chart analysis was conducted to evaluate the management of alcohol withdrawal in internal medicine patients at the study hospital (Ingram S, Wilbur K, unpublished results). The investigators found a high degree of variability in dosing regimens for benzodiazepines, a high overall rate of adverse outcomes or complications despite treatment for alcohol withdrawal, and high inconsistency in treatment regimens. Study personnel identified an opportunity to optimize management of patients with alcohol withdrawal. In June 2007, a preprinted order set and protocol based on the CIWA-Ar (see Appendix 2, available online at www.cjhponline.ca/index.php/cjhp/issue/view/84/showToc) were implemented for the internal medicine service. The protocol incorporated a combination of fixed-schedule and symptomtriggered dosing of benzodiazepines, with a choice of 4 standardized fixed-schedule dosing regimens and the CIWAAr to guide doses of "as needed" benzodiazepines. Specialized education in using the CIWA-Ar protocol was organized for nursing staff, and pharmacy and medical staff were notified of initiation of the preprinted order.

Although many studies have established the benefit of symptom-triggered benzodiazepine dosing based on the CIWA-Ar protocol, we are not aware of any studies that have examined a combination approach. The primary objective of this study was to determine whether the severity and duration of alcohol withdrawal would be reduced with use of the Initial Alcohol Withdrawal Management-Internal Medicine protocol relative to practice before its implementation. The secondary objective was to assess safety and evaluate patterns of usage of the protocol, to determine areas for potential improvement.

\section{METHODS}

Two study periods were identified: before (October 2005 to April 2007) and after (October 2007 to April 2009) implementation of the protocol. For each period, medical inpatients 
admitted with a diagnosis of alcohol withdrawal were identified from International Classification of Diseases coding and the hospital's inpatient computer system.

Patients over 18 years of age were included if they had been admitted to the internal medicine service for a minimum stay of at least $24 \mathrm{~h}$ and if there was documentation in the chart of a presumed diagnosis of alcohol withdrawal. Patients in the post-protocol group had to have been admitted to one of the internal medicine wards where the protocol had been implemented and had to have received at least one dose of benzodiazepine according to the protocol. To simulate similar admission conditions, patients in the pre-protocol group had to have been transferred out of the emergency department at some time during their hospital stay and had to have received at least one dose of benzodiazepine for treatment of alcohol withdrawal.

Patients were excluded if they had a documented allergy or sensitivity to benzodiazepines or were pregnant at the time of admission. To avoid confounding withdrawal symptoms, we excluded patients with active opiate, benzodiazepine, or stimulant withdrawal; patients who presented with delirium presumed to be unrelated to alcohol withdrawal; patients with concurrent psychiatric disorders requiring admission to hospital; and patients admitted with seizure or seizure disorder unrelated to alcohol withdrawal. Patients with documented regular use of benzodiazepines within 30 days before admission, other than benzodiazepine at bedtime for sleep, were also excluded.

To assess the duration of alcohol withdrawal treatment and the total amount of benzodiazepine administered, patients with early discontinuation of alcohol withdrawal therapy were excluded. Early discontinuation was defined in the preprotocol group on the basis of transfer or discharge from the internal medicine service while receiving active withdrawal treatment (i.e., patient received a dose of medication for withdrawal within the preceding $24 \mathrm{~h}$ ) and in the post-protocol group as discontinuation before achieving 3 consecutive CIWA-Ar scores below 10. Patients who left against medical advice while still receiving active treatment for withdrawal were also excluded. To avoid bias in the results, these patients with early discontinuation were included in the analyses of secondary outcomes (excluding total benzodiazepine dose) and quality assurance outcomes.

The primary outcome was the duration of benzodiazepine treatment for alcohol withdrawal, defined as the time difference in hours between the first and last doses given in hospital, including doses given in the emergency department. Secondary outcomes included total (cumulative) benzodiazepine dose, defined as the total dose, in oral lorazepam dosage equivalents, received over the total duration of treatment. The incidence of severe complications of alcohol withdrawal, defined as hallucinations, use of restraints, admission to the intensive care unit (ICU), seizure, request for trained team response for behavioural emergency, delirium tremens, cardiovascular event, and death related to withdrawal, were also tabulated. We also examined the incidences of serious adverse outcomes of benzodiazepine treatment, defined as excess sedation (non-arousability), respiratory depression, need to hold benzodiazepine until less sedated, and use of flumazenil.

To gain an understanding of the patterns of usage of the protocol and to assess potential hospital-wide functionality, data relating to quality assurance outcomes were collected. We examined whether the protocol was warranted for the patients to whom it had been applied, as defined by the following criteria: alcohol intake during the week before admission to hospital of 4 or more drinks per day for men or 2 or more drinks per day for women, score of 2 or above on the CAGE questionnaire for evaluating alcoholism, or history of a previous withdrawal episode or seizure. Delays in initiation and administration of the protocol were calculated to assess potential hindrance caused by restriction of the protocol to the Medical Assessment Unit and the internal medicine wards. We also evaluated adherence to the protocol and CIWA-Ar monitoring by nursing staff.

Ethics approval was obtained from the University of British Columbia Clinical Research Ethics Board.

\section{Statistical Analysis}

A sample-size calculation was performed for the primary outcome variable using $\alpha=0.05$ and power $=80 \%$ to show a difference in benzodiazepine treatment duration as small as $30 \mathrm{~h}$. Previous studies comparing symptom-triggered and non-symptom-triggered dosing have shown mean differences of about $40 \mathrm{~h}$ in duration of benzodiazepine treatment between the 2 strategies. We designed our study to show a difference as small as $30 \mathrm{~h}$ because the protocol used a combination of fixeddose and symptom-triggered dosing and may have led to a smaller improvement in treatment duration. Using numbers derived from an unpublished study conducted at another local hospital by one of the investigators (where mean withdrawal duration was $80 \mathrm{~h}$ for the pre-intervention group and $50 \mathrm{~h}$ for the post-intervention group, for a 30-h difference, with standard deviation $[S D]$ of $55 \mathrm{~h}$ ), we calculated a required sample size of 53. To allow for inclusion of patients not evaluable for the primary outcome (but included for the secondary analysis) and to account for the use of a nonparametric test, we increased the sample size to 70 per group.

Data were entered into an Excel (Microsoft, Redmond, Washington) spreadsheet and were analyzed with SPSS statistical software (PASW [Predictive Analytics SoftWare] Statistics). Nonparametric statistics were chosen because the primary outcome variable, duration of benzodiazepine use, was 
not normally distributed. The median duration of benzodiazepine treatment and the median total benzodiazepine dose for withdrawal were compared for the primary outcome using the Mann-Whitney $U$ test. The proportions of patients experiencing severe alcohol withdrawal syndrome and serious adverse outcomes of treatment and the proportions using adjunctive medications were analyzed with the $\chi^{2}$ test. $P$ values less than 0.05 were considered statistically significant. Standard descriptive statistics were employed to summarize the patients' demographic and clinical features.

\section{RESULTS}

Of the 438 admissions reviewed, 159 were included after application of the inclusion and exclusion criteria (Table 1). Of these, 71 in the pre-protocol group and 72 in the post-protocol group were assessable for the primary outcome (Table 2). Many of the patients whose admissions were reviewed were not admitted to the internal medicine service and were therefore excluded from the study. The most common reasons for exclusion were admission with seizure or seizure disorder unrelated to alcohol withdrawal, regular use of benzodiazepines before admission, and no doses of benzodiazepine after transfer out of the emergency department. For patients with multiple admissions during the specified time periods, data for each admission were tabulated as discrete accounts. All 159 admissions were included in the evaluation of safety outcomes, and all 79 post-protocol admissions were assessed for quality assurance outcomes.

Baseline demographic characteristics (Table 2) were comparable between the pre- and post-protocol groups, with an average age of 54 (SD 10) years and 56 (SD 34) years, respectively. The percentage of admissions in which alcoholism was the primary diagnosis was lower in the pre-protocol group (61\% versus $71 \%)$. Fewer patients in the pre-protocol group had addictions to nicotine or other drugs of abuse $(59 \%$ versus $75 \%$ ), but they also had a slightly higher incidence of prior alcohol withdrawal in hospital (59\% versus 54\%), previous withdrawal seizures ( $41 \%$ versus $35 \%$ ), and previous delirium tremens (13\% versus $10 \%)$. The median duration of the hospital stay was 5.6 (interquartile range [IQR] 3.6-9.3) days for the pre-protocol group and 3.5 (IQR 2.0-6.0) days for the post-protocol group.

Table 1. Reasons for Exclusion from Study or Early Discontinuation*

\begin{tabular}{|c|c|c|}
\hline \multirow[b]{2}{*}{ Reason } & \multicolumn{2}{|c|}{$\begin{array}{l}\text { Timing in Relation to } \\
\text { Implementation of Protocol }\end{array}$} \\
\hline & Before & After \\
\hline \multicolumn{3}{|l|}{ Exclusion from study } \\
\hline Active opiate, benzodiazepine, or stimulant withdrawal & 0 & 1 \\
\hline Presenting with delirium unrelated to alcohol withdrawal & 5 & 2 \\
\hline Concurrent psychiatric disorder requiring admission to hospital & 2 & 6 \\
\hline Admission with seizure or seizure disorder unrelated to alcohol withdrawal & 14 & 9 \\
\hline Regular use of benzodiazepine for 30 days or more before admission & 4 & 8 \\
\hline $\begin{array}{l}\text { No benzodiazepines given for treatment of alcohol withdrawal after transfer } \\
\text { out of emergency department }\end{array}$ & 9 & 4 \\
\hline Not assessable (incomplete information) & 8 & 7 \\
\hline \multicolumn{3}{|l|}{ Before implementation of protocol } \\
\hline Not admitted to internal medicine service with minimum $24 \mathrm{~h}$ stay in hospital & 83 & NA \\
\hline Not transferred out of emergency department during hospital stay & 13 & NA \\
\hline Diagnosis of alcohol withdrawal not documented in chart & 9 & NA \\
\hline \multicolumn{3}{|l|}{ After implementation of protocol } \\
\hline $\begin{array}{l}\text { Protocol not used because patient not admitted to Medical Assessment Unit } \\
\text { or Acute Medical Unit }\end{array}$ & NA & 91 \\
\hline $\begin{array}{l}\text { Appropriate non-use of protocol despite admission to Medical Assessment } \\
\text { Unit or Acute Medical Unit }\end{array}$ & NA & 4 \\
\hline \multicolumn{3}{|l|}{ Early discontinuation } \\
\hline \multicolumn{3}{|l|}{ Before implementation of protocol } \\
\hline $\begin{array}{l}\text { Transferred off internal medicine service while receiving active treatment for } \\
\text { withdrawal (benzodiazepine dose within last } 24 \mathrm{~h} \text { ) }\end{array}$ & 6 & NA \\
\hline $\begin{array}{l}\text { Left against medical advice while receiving active treatment for withdrawal } \\
\text { (benzodiazepine dose within last } 24 \mathrm{~h} \text { ) }\end{array}$ & 3 & NA \\
\hline \multicolumn{3}{|l|}{ After implementation of protocol } \\
\hline Protocol discontinued before 3 instances of CIWA-Ar score $<10$ & NA & 7 \\
\hline
\end{tabular}


Table 2. Baseline Characteristics of Patients for Admissions Included in Analysis of Primary Outcomes*

\begin{tabular}{|c|c|c|}
\hline \multirow[b]{2}{*}{ Characteristic } & \multicolumn{2}{|c|}{$\begin{array}{l}\text { Timing in Relation to Implementation of Protocol; } \\
\text { No. (\%) of Admissions* }\end{array}$} \\
\hline & Before $(n=71)$ & After $(n=72)$ \\
\hline Patient age, mean \pm SD (years) & $54 \pm 10$ & $56 \pm 34$ \\
\hline Patient sex, female & $15(21) 12(17)$ & \\
\hline \multicolumn{3}{|l|}{ Social history (addictions) } \\
\hline Nicotine & $37(52)$ & $48(67)$ \\
\hline Cocaine & $9(13)$ & $13(18)$ \\
\hline Heroin, opiate & $4 \quad(6)$ & $6 \quad(8)$ \\
\hline Marijuana & $9(13)$ & $11(15)$ \\
\hline Other & $1 \quad(1)$ & 3 (4) \\
\hline \multicolumn{3}{|c|}{ History of alcohol withdrawal syndrome } \\
\hline Prior hospital admission & $42(59)$ & $39(54)$ \\
\hline Prior withdrawal seizure & $29(41)$ & $25(35)$ \\
\hline Prior delirium tremens & $9(13)$ & $7(10)$ \\
\hline \multicolumn{3}{|l|}{ Primary diagnosis } \\
\hline Alcoholism & $43(61)$ & $51(71)$ \\
\hline Cardiac disease & $3 \quad(4)$ & $0 \quad(0)$ \\
\hline Diabetes mellitus & $2 \quad(3)$ & $1 \quad(1)$ \\
\hline Gastrointestinal disease & $7(10)$ & $5 \quad(7)$ \\
\hline Infection & $10(14)$ & $10(14)$ \\
\hline Pancreatitis & 2 (3) & 3 (4) \\
\hline Respiratory disease & $3 \quad(4)$ & $1 \quad(1)$ \\
\hline Other & $7(10)$ & $9(12)$ \\
\hline \multicolumn{3}{|c|}{ Secondary diagnosis or comorbidities } \\
\hline Alcoholism & $28(39)$ & $22(31)$ \\
\hline Cardiac disease & $25(35)$ & $24(33)$ \\
\hline Diabetes mellitus & $11(15)$ & $11(15)$ \\
\hline Fluid or electrolyte problem & $9(13)$ & $5 \quad(7)$ \\
\hline Gastrointestinal disease & $7(10)$ & $10(14)$ \\
\hline Hematologic condition & $2 \quad(3)$ & 2 (3) \\
\hline Hepatic disease & $27(38)$ & $26(36)$ \\
\hline Infection & $10(14)$ & 2 (3) \\
\hline Malignancy & $5 \quad(7)$ & $3 \quad(4)$ \\
\hline Musculoskeletal condition & $9(13)$ & $12(17)$ \\
\hline Neurological disease & $2(3)$ & 2 (3) \\
\hline Pancreatitis & $10(14)$ & $6 \quad(8)$ \\
\hline Psychiatric condition & $23(32)$ & $29(40)$ \\
\hline Respiratory disease & $11(15)$ & $5 \quad(7)$ \\
\hline Other & $16(23)$ & $20(28)$ \\
\hline
\end{tabular}

$\mathrm{SD}=$ standard deviation.

*For patients with more than one admission during the study periods, data were analyzed according to the number of admissions.

The median duration of benzodiazepine treatment for alcohol withdrawal declined significantly after introduction of the combination protocol: 91 (IQR 56-132) h for the preprotocol group versus 57 (IQR 28-101) h for the postprotocol group $(p<0.001)$ (Table 3). The total cumulative benzodiazepine dose per admission was 20.0 (IQR 10.0-43.0) $\mathrm{mg}$ in the pre-protocol group and 15.5 (IQR 6.9-30.0) $\mathrm{mg}$ in the post-protocol group $(p=0.026)$, corresponding to a reduction in both the cumulative fixed-schedule dose $(6.5 \mathrm{mg}$ versus $4.8 \mathrm{mg}$ ) and the cumulative symptom-triggered dose (11 mg versus $8.5 \mathrm{mg}$ ). Symptom-triggered benzodiazepine doses were given in 69 (97\%) of the 71 pre-protocol admissions and $69(96 \%)$ of the 72 post-protocol admissions, whereas fixed-schedule benzodiazepine doses were given in 49 (69\%) of the 71 pre-protocol admissions and 64 (89\%) of the 72 postprotocol admissions. Symptom-triggered doses were not administered in $2(3 \%)$ of the 71 pre-protocol admissions and in $3(4 \%)$ of the 72 of post-protocol admissions.

The number of patients experiencing one or more severe complications of alcohol withdrawal declined significantly after implementation of the protocol $(50 \%$ versus $33 \%$; $p=0.019)$, with the greatest absolute reductions in the incidences of 
Table 3. Duration of Benzodiazepine Therapy for Alcohol Withdrawal and Total (Cumulative) Benzodiazepine Dose (Lorazepam Equivalents*)

\begin{tabular}{|c|c|c|c|}
\hline \multirow[b]{2}{*}{ Outcome } & \multicolumn{2}{|c|}{$\begin{array}{l}\text { Timing in Relation to } \\
\text { Implementation of Protocol }\end{array}$} & \multirow[b]{2}{*}{$p$ Value } \\
\hline & Before $(n=71)$ & After $(n=72)$ & \\
\hline \multicolumn{4}{|l|}{ Primary } \\
\hline Median duration of benzodiazepine therapy (IQR) (h) & $91(56-132)$ & $57(28-101)$ & $<0.001$ \\
\hline \multicolumn{4}{|l|}{ Secondary } \\
\hline $\begin{array}{l}\text { Median cumulative benzodiazepine dose (IQR) } \\
\left(\mathrm{mg}, \text { lorazepam equivalents }{ }^{\star}\right)\end{array}$ & $20.0(10.0-43.0)$ & $15.5(6.9-30.0)$ & 0.026 \\
\hline $\begin{array}{l}\text { Total fixed-schedule benzodiazepine dose } \\
(\mathrm{mg}, \text { lorazepam equivalents*) }\end{array}$ & 6.5 & 4.8 & \\
\hline $\begin{array}{l}\text { Total symptom-triggered benzodiazepine dose } \\
\left(\mathrm{mg} \text {, lorazepam equivalents }{ }^{\star}\right)\end{array}$ & 11.0 & 8.5 & \\
\hline Median duration of hospital stay (IQR) (days) & $5.6(3.6-9.3)$ & $3.5(2.0-6.0)$ & $<0.001$ \\
\hline
\end{tabular}

hallucinations and use of restraints (Table 4). The occurrence of serious adverse outcomes of benzodiazepine treatment was not statistically different between the 2 groups ( $24 \%$ in the preprotocol group versus $16 \%$ in the post-protocol group, $p=0.25)$. Protocol-guided treatment of alcohol withdrawal was also associated with a statistically significant reduction in use of adjunctive medications ( $65 \%$ versus $38 \%, p=0.001$ ), with the greatest absolute reductions in the use of haloperidol, loxapine, quetiapine, and valproic acid.

All of the patients, except one in the pre-protocol group, received at least one dose of lorazepam, and at least one dose of diazepam was given in $44(55 \%)$ of the pre-protocol admissions and 28 (35\%) of post-protocol admissions (Table 4). No other benzodiazepines were used in the post-protocol group, but in the pre-protocol group, clonazepam was given in 2 admissions and midazolam in 1 admission. The mean number of benzodiazepine types administered was 1.58 (SD 0.57) in the preprotocol group and 1.35 (SD 0.48) in the post-protocol group.

\section{Quality Assurance Outcomes}

Patterns of usage of the protocol in the post-protocol group were reviewed for quality assurance (Table 5). Use of the protocol was deemed to have been warranted in all 79 of the post-protocol admissions reviewed, and for $47 \%$ of the admissions, the patient had at least one previous documented alcohol withdrawal episode. For comparison purposes, protocol use would have been warranted in all but one of the preprotocol admissions.

Because the protocol was implemented only on specific hospital wards and not in the emergency department, a delay from the time of admission to initiation and administration of the protocol was inevitable. We evaluated the median length of time for the various steps leading to eventual administration of the alcohol withdrawal protocol (Table 5). Overall, the median time from diagnosis of alcohol withdrawal syndrome to the first
CIWA-Ar scoring was 12 (IQR 8-23) h. For the 72 patients who completed treatment, the protocol was in effect for a median duration of 60 (IQR 39-95) h.

Various parameters were evaluated to assess caregivers' adherence to the protocol. CIWA-Ar monitoring was completed exactly as per protocol in only 17 (24\%) of the 72 admissions. Adherence with symptom-triggered benzodiazepine dosing, as per CIWA-Ar scoring, was also inconsistent. In particular, a mean of 1.1 (SD 1.8) benzodiazepine doses were administered despite CIWA-Ar scores less than 10 (i.e., when patients should not have received a dose), and a mean of 2.6 (SD 4.4) benzodiazepine doses were not administered despite CIWA-Ar scores of 10 or higher (i.e., when patients should have received a dose). In addition, a mean of 1.3 (SD 2.0) symptom-triggered doses were given without evaluating the CIWA-Ar score. Timely tapering of fixed-schedule dosing as prompted by the protocol occurred for only $33(46 \%)$ of the admissions. The mean number of fixed-schedule doses received after CIWA-Ar scores were consistently below 10 was 3.8 (SD 4.9), and the median length of time from the first CIWA-Ar score below 10 to the last dose of benzodiazepine was 13 (IQR 0-46) h. Overall, the median duration from the first benzodiazepine dose to the first persistent CIWA-Ar score below 10 was 47 (IQR 23-68) h.

\section{DISCUSSION}

In this study, implementation of an alcohol withdrawal protocol with combination fixed-schedule and symptomtriggered benzodiazepine dosing was associated with improved efficacy and safety of alcohol withdrawal treatment for medical inpatients relative to usual care before implementation of the protocol. A higher benzodiazepine dose was given over a shorter period in the post-protocol group, which signifies that patients were treated more aggressively, with outcomes of reduced treat- 


\section{Table 4. Secondary Outcomes}

\begin{tabular}{|c|c|c|c|}
\hline \multirow[b]{2}{*}{ Outcome } & \multicolumn{2}{|c|}{$\begin{array}{l}\text { Timing in Relation to } \\
\text { Implementation of Protocol; } \\
\text { No. }(\%) \text { of Patients* }\end{array}$} & \multirow[b]{2}{*}{$p$ Value } \\
\hline & Before $(n=80)$ & After $(n=79)$ & \\
\hline Severe complications of alcohol withdrawalt & $40(50)$ & $26(33)$ & 0.019 \\
\hline Hallucinations & $27(34)$ & $14(18)$ & \\
\hline Use of restraints & $25(31)$ & $15(19)$ & \\
\hline Admission to intensive care unit & $1 \quad(1)$ & $1 \quad(1)$ & \\
\hline Seizure & $5 \quad(6)$ & 3 (4) & \\
\hline Request for trained team response to behavioural emergency & $2(2)$ & $0 \quad(0)$ & \\
\hline Delirium tremens & $8(10)$ & $6 \quad(8)$ & \\
\hline Serious adverse outcomes of treatment with benzodiazepines & $\$ 19(24)$ & $13(16)$ & 0.25 \\
\hline Excess sedation (non-arousability) & $6 \quad(8)$ & $5 \quad(6)$ & \\
\hline Need to hold benzodiazepines until less sedated & $12(15)$ & $8(10)$ & \\
\hline Falls due to excess sedation & $4 \quad(5)$ & $4 \quad(5)$ & \\
\hline $\begin{array}{l}\text { Use of adjunctive medications for treatment } \\
\text { of alcohol withdrawal }\end{array}$ & $52(65)$ & $30(38)$ & 0.001 \\
\hline Clonidine & 1 (1) & $0 \quad(0)$ & \\
\hline Haloperidol & $10(12)$ & $2 \quad(3)$ & \\
\hline Loxapine & $36(45)$ & $21(27)$ & \\
\hline Phenobarbital & $1 \quad(1)$ & $1 \quad(1)$ & \\
\hline Phenytoin & $5 \quad(6)$ & $1 \quad(1)$ & \\
\hline Quetiapine & $25(31)$ & $8(10)$ & \\
\hline Valproic acid & $8(10)$ & $1 \quad(1)$ & \\
\hline Other & 3 (4) & $1 \quad(1)$ & \\
\hline Use of benzodiazepines & & & NA \\
\hline Diazepam & $44(55)$ & $28(35)$ & \\
\hline Lorazepam & $79(99)$ & $79(100)$ & \\
\hline Clonazepam & $2(2)$ & $0 \quad(0)$ & \\
\hline Midazolam & $1 \quad(1)$ & $0 \quad(0)$ & \\
\hline Median no. of benzodiazepines used & 1.58 & 1.35 & \\
\hline Evidence of alcohol withdrawal to warrant use of protocol§ & $70(99)$ & $72(100)$ & NA \\
\hline Men: 4 or more drinks per day in past week & $56(79)$ & $59(82)$ & \\
\hline Women: 2 or more drinks per day in past week & $14(20)$ & $11(15)$ & \\
\hline CAGE score 2 or above & $32(45)$ & $14(19)$ & \\
\hline Past withdrawal episode(s) & $40(56)$ & $34(47)$ & \\
\hline Past withdrawal seizure(s) & 27 (38) & $19(26)$ & \\
\hline
\end{tabular}

NA = not applicable.

*Except where indicated otherwise.

tCardiovascular events and deaths were also assessed, but there were no patients with either of these severe complications.

¥Respiratory depression and use of flumazenil were also assessed, but there were no patients with either of these severe adverse outcomes of benzodiazepine therapy.

$\S$ Percentages for this section are based on the number of admissions included in the primary analysis

(i.e., 71 for the pre-protocol group and 72 for the post-protocol group).

ment duration and cumulative benzodiazepine dose. Although there were fewer severe adverse outcomes of benzodiazepines in the post-protocol group than in the pre-protocol group, the difference was not statistically significant. There were few severe adverse outcomes overall, so the failure to detect a significant difference may have resulted from the small sample size. Regardless, the protocol has not increased risks or introduced disadvantages in relation to any of these parameters.

Although the 2 study groups were similar in terms of baseline characteristics, patients in the pre-protocol group had a less extensive addiction history, which may imply that they had less severe alcohol addiction. However, this was offset by the more extensive alcohol withdrawal history in this group, which might have been associated with a higher risk of severe complications of alcohol withdrawal.

Previous studies have established the advantages of protocols based exclusively on symptom-triggered benzodiazepine dosing, typically comparing this form of dosing with usual care, where fixed-schedule and symptom-triggered dosing are prescribed without guidance from a protocol. This study has 


\section{Table 5. Quality Assurance Outcomes after Implementation of Protocol} (72 Admissions)

\begin{tabular}{|c|c|}
\hline Outcome & $\begin{array}{l}\text { Median }(\mathrm{IQR}) \text {, Mean } \pm \text { SD, } \\
\text { or Other Measure }(n=72)\end{array}$ \\
\hline $\begin{array}{l}\text { Median time from hospital admission to ordering of alcohol } \\
\text { withdrawal protocol }(\mathrm{h})\end{array}$ & $7(5-10)$ \\
\hline $\begin{array}{l}\text { Median time from diagnosis of alcohol withdrawal syndrome to } \\
\text { ordering of alcohol withdrawal protocol }(\mathrm{h})\end{array}$ & $6(5-8)$ \\
\hline $\begin{array}{l}\text { Median time from ordering of alcohol withdrawal protocol to } \\
\text { first CIWA-Ar score }(h)\end{array}$ & $3(1-13)$ \\
\hline $\begin{array}{l}\text { Median time from diagnosis of alcohol withdrawal syndrome } \\
\text { to first CIWA-Ar score }(\mathrm{h})\end{array}$ & $12(8-23)$ \\
\hline $\begin{array}{l}\text { Median duration for which alcohol withdrawal protocol } \\
\text { was in effect (h) }\end{array}$ & 60 (39-95) \\
\hline $\begin{array}{l}\text { Mean no. of symptom-triggered doses administered per patient } \\
\text { despite CIWA-Ar score }<10\end{array}$ & $1.1 \pm 1.8$ \\
\hline $\begin{array}{l}\text { Mean no. of prn doses of benzodiazepines administered } \\
\text { without evaluating CIWA-Ar score }\end{array}$ & $1.3 \pm 2.0$ \\
\hline $\begin{array}{l}\text { Mean no. of prn lorazepam doses not administered despite } \\
\text { CIWA-Ar score of } 10 \text { or higher }\end{array}$ & $2.6 \pm 4.4$ \\
\hline No. (\%) of admissions with fixed-schedule dosing & $64 \quad(89)$ \\
\hline $\begin{array}{l}\text { No. (\%) of admissions with CIWA-Ar monitoring at specified } \\
\text { time intervals as dictated in protocol }\end{array}$ & $17 \quad(24)$ \\
\hline $\begin{array}{l}\text { No. }(\%) \text { of admissions with regular benzodiazepine tapered if } \\
\text { CIWA-Ar score }=0-9\end{array}$ & $33(46)$ \\
\hline $\begin{array}{l}\text { Mean no. of regular benzodiazepine doses received if } \\
\text { CIWA-Ar score }<10\end{array}$ & $3.8 \pm 4.9$ \\
\hline Time from first CIWA-Ar score of 0-9 to last dose of benzodiazepine & $13(0-46)$ \\
\hline No. (\%) of admissions without any CIWA-Ar scores > 10 & 31 (43) \\
\hline $\begin{array}{l}\text { Time from first benzodiazepine dose to first persistent } \\
\text { CIWA-Ar score }<10(\mathrm{~h})\end{array}$ & $47(23-68)$ \\
\hline
\end{tabular}

demonstrated that a protocol combining fixed-schedule and symptom-triggered dosing can also yield benefit and may serve as an alternative to protocols based on symptom-triggered dosing alone, although it is recognized that improvements in outcome may be more limited with the combined approach. In typical studies examining regimens with symptom-triggered dosing only, the duration of medication treatment was reduced by about $70 \%$ to $80 \%,{ }^{8,9}$ whereas the reduction in duration of benzodiazepine therapy was only $37 \%$ in the study reported here. Likewise, total benzodiazepine equivalents were typically decreased by approximately $80 \%$ with symptom-triggered regimens $s^{8,9}$ but decreased by only $22 \%$ in the current study.

Using a protocol increases the uniformity of treatment, especially in large teaching hospitals where regimens are prescribed by physicians of varied experiences and expertise. The results of the current study supported this observation, as fewer benzodiazepine types and fewer adjunctive medications were used for the post-protocol admissions. The guided fixedschedule dosing combined with CIWA-Ar-dictated, symptomtriggered dosing may help to minimize the disadvantages of unguided combination dosing relative to symptom-triggered dosing alone.
Although symptom-triggered dosing regimens have been well studied and are well recognized for the treatment of alcohol withdrawal, they have not been universally adopted, possibly because institutions are unable to carry out the required CIWA-Ar monitoring. The CIWA-Ar protocol dictates the period for which monitoring is required and whether a benzodiazepine dose should be administered. Hesitation in trusting exclusively symptom-triggered dosing may stem from lack of staff who are trained and familiar with the CIWA-Ar-based alcohol withdrawal protocol. In our study, consistent monitoring was confirmed as an issue of concern, as fewer than half of the admissions had perfect adherence with the CIWA-Ar scoring, as per protocol. Fixed-schedule dosing may have functioned as a type of buffer: in the event that CIWA-Ar scoring was missed and a required symptomtriggered dose was not administered, the patient would still have received the sedating and anticonvulsant effects of the fixed-schedule doses.

The inclusion of fixed-schedule doses in the protocol may prolong the duration of treatment and lead to overtreatment of patients. In this study, fixed-schedule dosing was tapered as prompted by the protocol for only 33 (46\%) of the 72 patients. 
Treatment extended a median of 13.1 hours beyond when fixed-schedule dosing should have been tapered, with patients receiving an average of 3.8 doses after CIWA-Ar scores were consistently below 10 . Thirty-one (43\%) admissions had no CIWA-Ar scores above 10, which indicates that these patients may have been overtreated: the fixed-schedule doses that these patients received would not have been warranted under a protocol based exclusively on symptom-triggered dosing. However, it is possible that these continued benzodiazepine doses prevented further withdrawal symptoms, helping to keep the CIWA-Ar scores below 10 .

A protocol combining fixed-schedule and symptomtriggered dosing may also be preferable in situations when CIWA-Ar scoring cannot be accurately completed. In a study of medical and surgical inpatients, Hecksel and others ${ }^{12}$ found that the protocol was inappropriately applied to more than half of the patients, many of whom were unable to respond reliably to the CIWA-Ar questions. In these cases, the addition of protocol-guided, fixed-schedule dosing might reduce the risk of undertreating patients because of inaccurate CIWA-Ar scores. Detection of true differences between the combination dosing protocol and an exclusively symptom-triggered dosing protocol will require a future trial directly comparing the 2 approaches.

Because the alcohol withdrawal protocol in this study was implemented only in the acute care internal medicine wards, the question arises of whether expansion to hospital-wide use is appropriate. Implementation in at least the emergency department would help to reduce the delay in initiating the protocol for individual patients and might therefore further increase the benefits observed with the protocol. Caution must be exercised in using the protocol in other wards and for patients with other major comorbidities, as certain complex comorbidities might be confused with alcohol withdrawal. Staff must be trained to recognize cases for which the protocol is appropriate and must be able to commit to the frequent and regular CIWA-Ar monitoring required.

This study had several limitations, primarily because of its retrospective design and the fact that the 2 study groups were sampled from different periods in a nonrandomized fashion. It is possible that the 2 study groups were fundamentally different, especially given that the post-protocol group appeared to have a more severe addiction history. Although the majority of reviewed admissions involved internal medicine patients, the pre-protocol group also included patients who had been admitted to wards other than the internal medicine ward; differences in comorbidities for these patients might also increase the risk that the 2 study populations differed. It would have been insightful to compare CIWA-Ar scores to determine withdrawal severity over the course of treatment, but the CIWA-Ar scores were only sporadically documented for the pre-protocol group and only for selected admissions. The chart review nature of this study introduced innate limitations in terms of potential bias and missing data. Although the same investigator collected the data for all admissions, the involvement of many different physicians increased the risk of inconsistencies in assessment and inaccuracies in documentation.

The shorter median duration of hospital stay for the postprotocol group (3.5 days versus 5.6 days in the pre-protocol group) cannot be assumed to result solely from implementation of the protocol. Hospital culture has changed in the years since the pre-protocol period, with a variety of new approaches to promote earlier discharge. However, the earlier resolution of alcohol withdrawal syndrome associated with use of the protocol is likely to contribute to decreasing duration of hospital stay, playing a role in improving patient outcomes and reducing hospital costs.

\section{CONCLUSIONS}

A combination fixed-schedule and symptom-triggered alcohol-withdrawal protocol for dosing of benzodiazepines in a medical ward was associated with a shorter duration of benzodiazepine use and fewer patients experiencing severe complications of alcohol withdrawal.

\section{References}

1. Bayard M, McIntyre J, Hill KR, Woodside J Jr. Alcohol withdrawal syndrome. Am Fam Physician 2004;69(6):1443-1450.

2. Vincent WR, Smith KM, Lewis DA, Winstead S. Review of alcohol withdrawal in the hospitalized patient: diagnosis and assessment. Orthopedics 2007;30(5):358-361.

3. Mayo-Smith MF. Pharmacological management of alcohol withdrawal. A meta-analysis and evidence-based practice guideline. American Society of Addiction Medicine Working Group on Pharmacological Management of Alcohol Withdrawal. JAMA 1997;278(2):144-151.

4. Sullivan JT, Skykora K, Schneiderman J, Naranjo A, Sellers EM. Assessment of alcohol withdrawal: the revised clinical institute withdrawal assessment for alcohol scale (CIWA-Ar). Br J Addict 1989;84(11):1353-1357.

5. Jaeger TM, Lohr RH, Pankratz VS. Symptom-triggered therapy for alcohol withdrawal syndrome in medical inpatients. Mayo Clin Proc 2001;76(7):695-701.

6. Holbrook AM, Crowther R, Lotter A, Cheng C, King D. Diagnosis and management of acute alcohol withdrawal. CMAJ 1999;160(5):675-680.

7. Saitz R, Mayo-Smith MF, Roberts MS, Redmond HA, Bernard DR, Calkins DR. Individualized treatment for alcohol withdrawal. A randomized double-blind controlled trial. JAMA 1994;272(7):519-523.

8. Reoux JP, Miller K. Routine hospital alcohol detoxification practice compared to symptom triggered management with an objective withdrawal scale (CIWA-Ar). Am J Addict 2000;9(2):135-144.

9. Daeppen JB, Gache P, Landry U, Sekera E, Schweizer V, Gloor S, et al. Symptom-triggered vs fixed-schedule doses of benzodiazepine for alcohol withdrawal: a randomized treatment trial. Arch Intern Med 2002;162(10):1117-1121.

10. Weaver MF, Hoffman HJ, Johnson RE, Mauck K. Alcohol withdrawal pharmacotherapy for inpatients with medical comorbidity. $J$ Addict Dis 2006;25(2):17-24. 
11. Saitz R, Friedman LS, Mayo-Smith MF. Alcohol withdrawal: a nationwide survey of inpatient treatment practices. J Gen Intern Med 1995;10(9):479487.

12. Hecksel KA, Bostwick JM, Jaeger TM, Cha SS. Inappropriate use of symptom-triggered therapy for alcohol withdrawal in the general hospital. Mayo Clin Proc 2008;83(3):274-279.

Karen Ng, BSc(Pharm), ACPR, was, at the time this study was performed, a Clinical Pharmacist, Richmond Hospital, Richmond, British Columbia. She is now a PharmD student in the Faculty of Pharmaceutical Sciences, The University of British Columbia, Vancouver, British Columbia

Karen Dahri, BSC, BSC(Pharm), ACPR, PharmD, is a Clinical Pharmacy Specialist (Internal Medicine), Vancouver General Hospital, and a Clinical Assistant Professor, Faculty of Pharmaceutical Sciences, The University of British Columbia, Vancouver, British Columbia.
Ivy Chow, BSc(Pharm), ACPR, PharmD, is a Clinical Pharmacy Specialist (Infectious Diseases), Burnaby Hospital, Burnaby, British Columbia, and a Clinical Instructor, Faculty of Pharmaceutical Sciences, The University of British Columbia, Vancouver, British Columbia.

Michael Legal, BSc(Pharm), ACPR, PharmD, is a Clinical Pharmacy Specialist (Medicine), St Paul's Hospital, and a Clinical Assistant Professor, Faculty of Pharmaceutical Sciences, The University of British Columbia. Vancouver, British Columbia.

\section{Address correspondence to:}

Dr Karen Dahri

CSU Pharmaceutical Sciences

Vancouver General Hospital

855 West 12th Avenue

Vancouver BC V5Z $1 \mathrm{M} 9$

e-mail: Karen.Dahri@vch.ca 